\section{Plant and Environmental Factors Influencing the Pattern of Pigment Accumulation in 'Honeycrisp' Apple Peels Using a Novel Color Analyzer Software Tool}

\author{
Adriana Telias ${ }^{1}$ and Emily Hoover \\ Department of Horticultural Science, University of Minnesota, 1970 Folwell \\ Avenue, St. Paul, MN 55108
}

Diego Rother

Department of Electrical and Computer Engineering, University of Minnesota, 200 Union Street SE, Minneapolis, MN 55455

Additional index words. Malus pumila, anthocyanin, stripes, image processing, image segmentation

\begin{abstract}
One of the most important factors determining apple (Malus pumila P. Mill.) market acceptance is peel color. Coloring of 'Honeycrisp' fruits can adopt two patterns: blushed or striped. This is an unusual phenomenon in apple. The objective of this study was to compare 'Honeycrisp' fruit from trees that were propagated from buds occurring on branches carrying only blushed or striped fruit. We concluded that blushed trees tend to produce a higher percentage of blushed fruit than striped trees, indicating a mechanism conserved through cell division. The percentage of blushed fruit on any given tree changed from year to year. Blushed and striped fruit occurred together on the same branch, and even on the same spur, with fruits located in the outer canopy being more likely to be striped. Higher crop loads were associated with a lower percentage of blushed fruit on the tree. Blushed and striped fruit do not consistently differ in their maximum pigment accumulation before ripening. The comparison of average hue angle for the whole peel at harvest indicates that blushed fruit are redder on average. Stripes were caused by reduced anthocyanin accumulation in certain portions of the peel and not by deeper localization. We speculate that an epigenetic mechanism regulates the pattern of anthocyanin accumulation in 'Honeycrisp' apple. Increased production of blushed, redder apples may be achieved through clonal selection and crop load regulation. A software tool for efficient relative color evaluations was developed and is freely available to the community.
\end{abstract}

'Honeycrisp' is a cultivar developed by the University of Minnesota and released in 1991 (Luby and Bedford, 1992). Many of its characteristics have attracted growers and consumers, resulting in a major increase in production. Coloring of 'Honeycrisp' fruits can adopt two basic patterns: "blushed" or "striped" (Fig. 1). For the purposes of this study, fruits are blushed when the surface is partly covered with a red tinge that is not

HortScience Vol. 43(5) August 2008 anthocyanins, the primary red pigments in apple peel. Consequently, apple consumption has been associated with lowered risks of cancer, cardiovascular disease, and other chronic diseases (Boyer and Liu, 2004; Eberhardt et al., 2000; Knekt et al., 1996; Le Marchand et al., 2000).

Apple peel color is determined first by the ground color of the peel and second by the superimposed red anthocyanin pigmentation (if present). Anthocyanin can accumulate following different patterns: flecks, stripes, or blush, all of which can range widely in their intensity. These characters can be affected by environmental, nutritional, and cultural factors; the stage of maturity of the fruit; and by the microenvironment within the canopy (Janick et al., 1996). There are two peaks of anthocyanin accumulation in apple, the first occurring during the phase of intense cell division in the fruit and the second coinciding with ripening of red cultivars (Saure, 1990).

Anthocyanin can be found in the epidermis and subepidermal layers of the peel, but not all cells within a layer are pigmented. Some apples have no pigment in the epidermis, and the color intensity depends on the proportion of cells in each subepidermal layer that contains pigment. In the striped cultivars Delicious and Northern Spy, the difference in color between a stripe and the adjacent area is the result of the presence of more pigmented cells per unit area in red stripes. Color sports can differ from the cultivar from which they originated in the proportion of pigmented cells, the amount of anthocyanin accumulation in the cells, and the tissue layers in which anthocyanins accumulate (Dayton, 1959).

Color measurements in plants are performed using a variety of methods. Color assessment by comparison with color charts is the most economical, but also the most tedious and subjective. Colorimeters provide, at a higher cost, an objective measurement but usually of a localized area. To facilitate this work, we developed image processing software to make relative color measurements of "large" surface areas in an unlimited number of photos. Other software packages have been implemented to perform similar functions [e.g., detection of fruit blemishes; see Du and Sun (2004) and references therein], but to our knowledge, none of them can perform this function automatically on a large set of images and at the same time being freely available. A highthroughput image processing method that is fully automatic and that is made freely available to the academic community can be very valuable.

In this study, 'Honeycrisp' trees were propagated from buds occurring on branches with exclusively striped or blushed fruits to study the stability of the blushed and striped traits after asexual propagation. Contrary to the stable behavior of many apple color sports, preliminary observations indicated that 'Honeycrisp' trees propagated in this way did not consistently produce blushed or striped fruit over time. Additional objectives of this study were to determine whether 


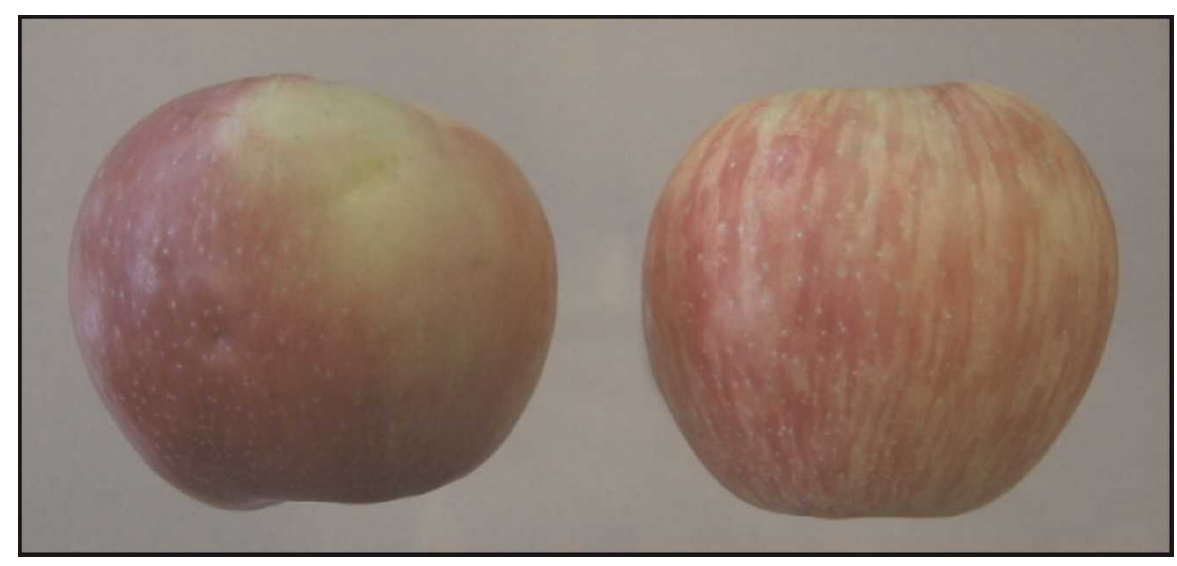

Fig. 1. Blushed (left) and striped (right) fruits of 'Honeycrisp' apple.

blushed and striped fruit are distributed on the tree following a consistent pattern that could be explained by environmental effects or plant conditions; to assess the effect of crop load on the percentage of blushed fruit on each tree; and finally to compare the timing, intensity, and location of anthocyanin accumulation in blushed and striped fruits.

\section{Materials and Methods}

Experiments were conducted during the 2005, 2006, and 2007 growing seasons at the University of Minnesota Horticultural Research Center in Chanhassen, $\mathrm{MN}\left(45^{\circ} \mathrm{N}\right)$. Preliminary data were collected in 2003 and 2004. 'Honeycrisp' trees used in this study were planted in 1999, on B.9 rootstock, at a $1.8-\mathrm{m}$ spacing within rows and $4.9 \mathrm{~m}$ between rows in a randomized fashion. A total of 73 of these trees were propagated from buds on 23 selected branches with exclusively blushed fruit (here referred to as "blushed trees") and 99 were propagated from 27 branches with exclusively striped fruit (here referred to as "striped trees"). Fruit was thinned each year after June drop on each tree to homogenize crop load, leaving $\approx 5$ fruit $/ \mathrm{cm}^{2}$ of trunk cross-sectional area. Leaf and soil analyses were performed in Aug. 2005.

For the 2005 color evaluations, 16 blushed trees that produced only blushed fruit and 16 striped trees that produced only striped fruit in 2004 were selected. The most intense red portion of the petals was measured on 10 tagged flowers per tree on $29 \mathrm{Apr}$. (pink blossom) using the Royal Horticultural Society (1995) color charts . Using the same trees, fruit color measurements at the most intense red portion of the peel were taken on 1 June with the color chart. We measured fruit color in 10 fruits per tree in early, mid-, and late August with a colorimeter (Minolta chroma meter CR-200; Minolta Camera Co., Ltd., Osaka, Japan) using the CIE $L^{*}, a^{*}, b^{*}$ system. Hue angle was estimated using the formulas provided by McGuire (1992) and reported in degrees $\left(0^{\circ}=\right.$ red-purple, $90^{\circ}=$ yellow, and $180^{\circ}=$ bluish green). Two measurements per fruit were taken on the reddest portion of the peel.
In 2006, 30 flowers were tagged, when available, only on the 16 blushed trees selected in 2005. This change in the way of selecting fruit was justified by the very low incidence of blushed fruit observed in 2005 on the selected blushed trees as well as on the block as a whole. Petal color measurements were taken on tagged flowers on $27 \mathrm{Apr}$. (pink blossom) using the color chart. The early June fruit color evaluation was not possible in 2006 as a result of absence of red coloration. Fruit color measurements were started on 15 June and performed every $18 \mathrm{~d}$ on average using the colorimeter. One measurement per fruit was taken.

Four branches per tree, carrying up to 15 fruits each, were selected on 32 trees that produced both kinds of fruits in 2004. Each year we recorded the number of blushed and striped fruit on each branch 1 week before harvest. All fruit was harvested each year and classified as striped or blushed for each tree individually and the percentage of blushed fruit was then calculated for each tree. In addition, in 2007, the intensity of the stripes was visually evaluated and fruits were scored as either weakly or strongly striped.

Each year, we took two (2005) or four (2006 and 2007) photographs per individual blushed and striped fruit after harvest; fruits were rotated $180^{\circ}$ (when two pictures were taken) or $90^{\circ}$ (when four pictures were taken) between pictures so that all the surface of each fruit appears in at least one picture (except for small areas at the top and bottom of the fruit). When four pictures were taken, every point on the fruit equator is seen exactly twice (once close to frontally), reducing the bias introduced by the orientation of the fruit chosen. Pictures were taken in the laboratory, under constant light conditions from fluorescent tubes, using a Canon digital camera model A75 (Canon, Tokyo) at $2048 \times$ 1536 (2005 and 2006) or $2816 \times 2112$ (2007) resolution. Translucent paper was placed between the source light and the fruit to avoid highlights. The images were then processed using the color analyzer software we developed. A total of 168,210, and 537 fruits were evaluated in 2005, 2006, and 2007, respectively. Color was also measured with a colorimeter in the reddest portion of the peel, except in 2005 because a high proportion of the fruit had been damaged by hail, and reddest areas were usually associated with this damage.

The color analyzer is a software tool developed in Matlab (Version 7.1; The Mathworks, Natick, MA) to measure statistics (e.g., mean color, color variance, and so on) of areas of interest in a set of pictures. The measurements are assumed to be made under unknown but constant illumination conditions. Therefore, the resulting color estimates are relative to these illumination conditions and can only be used for comparisons of pictures taken under the same conditions and not for absolute measurements. In an initial stage, the software must be "trained" (using this term as understood in the machinelearning community) to segment these areas. The user trains the program by selecting and labeling points in the picture as belonging to the class of interest (foreground) or to the rest of the picture (background). The training is interactive; the user selects some points and is shown the result of the segmentation and adds more points if necessary to correct the result until it is satisfactory. This training usually takes less than 15 min and is performed only once at the beginning of the photographic analysis process. Given the automatic nature of the process, no noticeable differences that can be attributed to variability among individual trainers of the program are observed. After the training is finished, the program automatically processes one picture at a time by first segmenting the area of interest and then computing the color statistics of this area (Fig. 2). To select the area of interest, each point in the image is classified as foreground or background using a nearest-neighbor classifier (Duda et al., 2001). The nearest-neighbor classifier assigns to each pixel the label of the closest (according to Euclidian distance in RGB space) training pixel. To remove small interspersed regions, two morphological operations (Gonzalez and Woods, 1992) are performed in sequence on the result of the classification; first, the closure operation and then the opening of the complement. The statistic computed for the selected region was its mean color, calculated in RGB coordinates and expressed in the hue, saturation, and value color space. Note that in this output, hues are also expressed in degrees. The output is automatically exported to Excel (Microsoft, Redmond, WA). The code can be obtained from the authors by request and can be used within Matlab or as a standalone application. Running the program within Matlab has the advantage that it can then be easily modified to return any other statistic of the segmented region (e.g., shape, area, visual appearance) of the crop of interest.

To study the distribution of blushed and striped fruit on individual trees and the effect of light interception, we used nine 30-yearold 'Honeycrisp' trees on M26 planted on the same farm at a 2.4-m spacing within rows and $4.9 \mathrm{~m}$ between rows. An upper (upper third of the canopy) and a lower (lower third of the canopy) scaffold branch was selected both on 
the southwest and northeast sides of the tree. Each branch was divided into an inner portion, extending $1 \mathrm{~m}$ from the trunk, and an outer portion, extending from $1 \mathrm{~m}$ out from the trunk to the branch tip. At the time of commercial harvest, we recorded the number of blushed, weakly striped, and strongly striped fruit on each branch and branch sector and noted whether they were single fruits or part of fruit clusters.

We observed multiple peel cross-sections to learn about the histological localization of anthocyanin-containing cells in both kinds of fruits. In striped fruits, we compared red and green stripes. Fruit peels were freehandsectioned from mature blushed and striped fruit using a razor blade. They were then mounted on glass slides with a drop of distilled water and examined using an optical microscope (Leitz, Wetzlar, Germany).

The incidence of blushed fruit and the effect of crop load on the incidence of blushed fruit were analyzed by binomial regression analysis in the program ARC (Cook and Weisberg, 1999). The effect of fruit position on the tree and frequencies of blushed, weakly, and strongly striped fruit were analyzed using $\chi^{2}$ tests and contrasts in SAS system for Windows, release 9.1 (SAS Institute Inc., Cary, NC). Color measurements for blushed and striped fruit were compared within each date using the procedure GLM of the SAS. The mean separation test used was least significance difference.

\section{Results and Discussion}

Blushed trees produced a significantly $(P<0.01)$ higher percentage of blushed fruit than striped trees in $2005(23.0 \%$ versus $5.0 \%), 2006(8.4 \%$ versus $2.2 \%)$, and 2007 ( $1.7 \%$ versus $0.2 \%$ ). Striped trees additionally produced fruit with a higher intensity of striping when compared with blushed trees with proportionally more fruit falling under the category of strongly striped $(96.6 \%$ versus $88.6 \%$ ) and less under weakly striped $(2.9 \%$ versus $8.1 \%)(P<0.01)$.

The percentage of blushed fruit on any given tree or branch changed from year to year. On trees carrying blushed fruit, higher crop loads were associated with lower percentage of blushed fruit (Fig. 3). The binomial regression models constructed using data from trees that produced at least one blushed fruit indicate a significant effect of the number of fruit per unit of trunk crosssectional area on the incidence of blushed fruit on individual trees for the 3 years $(P<$ $0.01)$. Models were statistically different among years. The increase in average crop load from 1.2 fruit $/ \mathrm{cm}^{2}$ in 2005 to 5.1 fruit/ $\mathrm{cm}^{2}$ in 2007 for the block as a whole may partially explain the decreasing percentages of blushed fruit observed. Additional factors that were not measured in this study such as climate variables, higher pest pressure, or others could have also influenced the behavior of the plants.

Observations performed on older 'Honeycrisp' trees indicated that the position of the
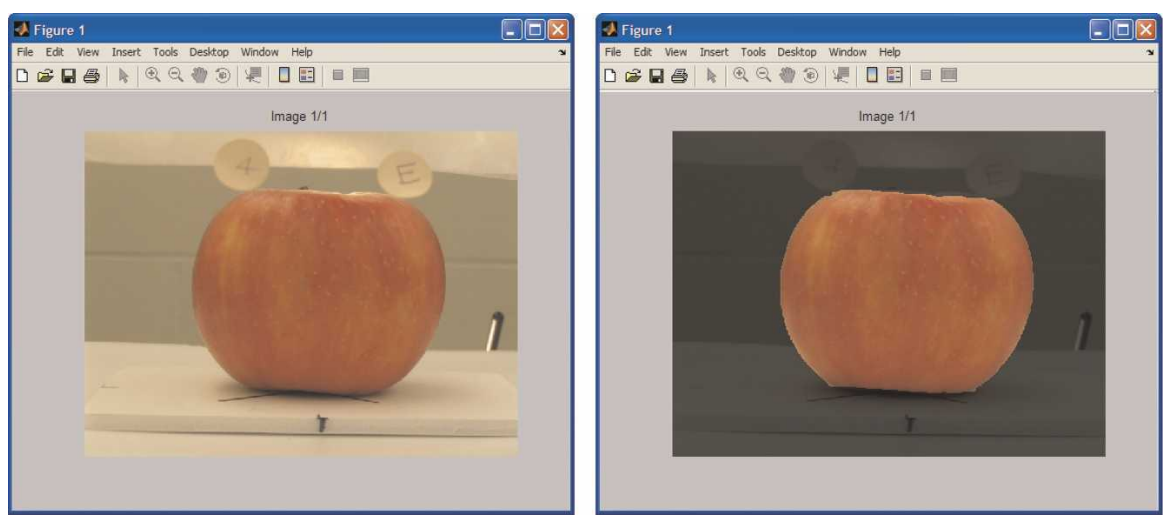

Fig. 2. Two screenshots of the implemented color analyzer software tool showing the original image (left) and the segmented result (right).

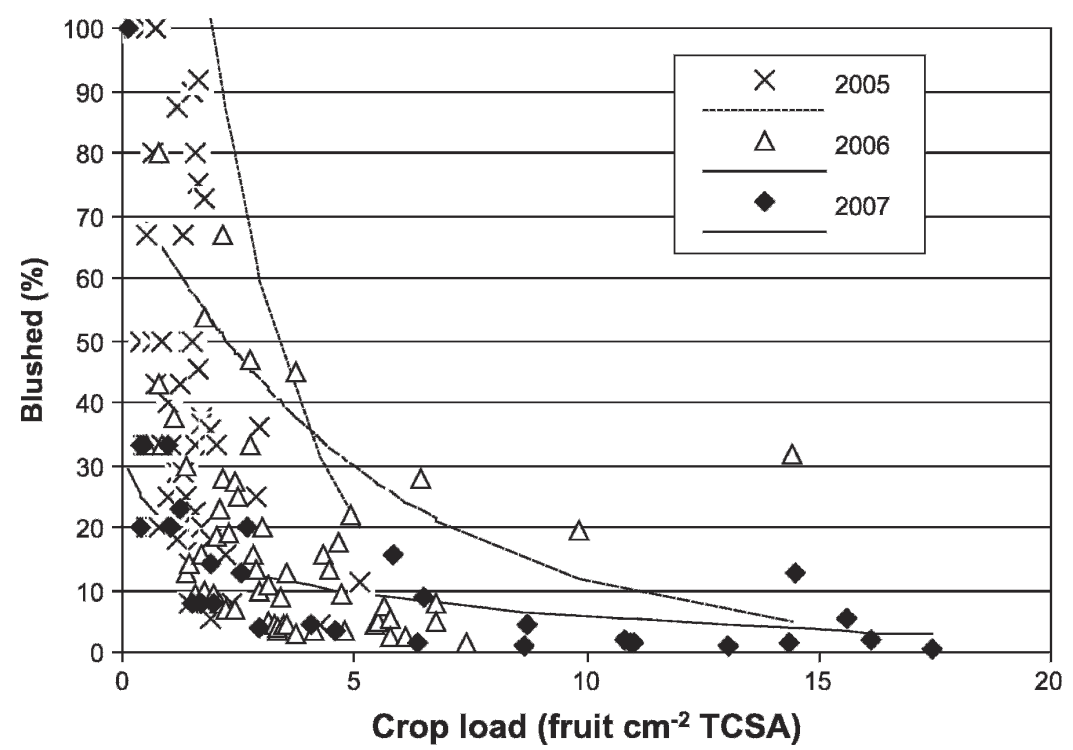

Fig. 3. Crop load (expressed as number of fruits per trunk cross-sectional area) and the percentage of blushed fruit for individual trees that produced at least one blushed fruit $(2005,2006$, and 2007). The equations for the models fitted are: Blushed $2005=\exp (0.31-0.51 * \mathrm{~F}) /[1+\exp (0.31-0.51 * \mathrm{~F})]$, Blushed $2006=$ $\exp \left(-0.96-0.19^{*} \mathrm{~F}\right) /\left[1+\exp \left(-0.96-0.19^{*} \mathrm{~F}\right)\right]$, and Blushed $2007=\exp \left(-1.87-0.099^{*} \mathrm{~F}\right) /[1+(-1.87-$ $0.099 * \mathrm{~F})$ ] where $\mathrm{F}$ is the number of fruits per square centimeter of trunk cross-sectional area.

fruit on the tree is related to the pattern of anthocyanin deposition. Thirteen percent of the fruit on northeast-facing branches was blushed as compared with only $6.0 \%$ on southwest-facing branches $(P<0.05)$. Lower branches and inner sections of the branches tended to produce more blushed fruit, but these differences were not statistically significant. Similar results were obtained when considering the intensity of stripes with southwest branches, which in addition to producing a higher percentage of striped fruit, also showed a significantly higher proportion $(76.4 \%$ versus $68.8 \%)$ of strongly striped fruit than the northeast branches $(P<0.0001)$. These results suggest that higher light incidence on the bud or the fruit correlates with an increase in the occurrence and strength of stripes.

Fruits within clusters were more likely $(P<0.01)$ to be all of the same kind (blushed, weakly, or strongly striped). This analysis took into account the relative probabilities of each type of apple on the tree. Although spurs carrying fruits of different kinds were observed, fruits in closer proximity were more likely to have similar phenotypes, suggesting the existence of a localized mechanism of regulation of the pattern of anthocyanin accumulation.

We did not find significant differences in petal color when comparing blushed and striped fruit. In 2005, blushed fruit measured early in development (1 June) were darker than striped fruit. This early fruit evaluation could not be performed in 2006 as a result of absence of red coloration at this stage. This was probably a consequence of weather conditions more conducive to faster pigment degradation than in the previous year. Blushed fruits in 2005 were significantly redder (color measured at reddest point) than striped fruit on 23 Aug. $(P<0.05)$ with a similar trend observed in earlier dates (Fig. 4). Differences in color between blushed and striped fruit were not observed in 2006 (Fig. 
4) or 2007. Collectively, these data indicated no consistent differences in maximum pigment accumulation during fruit development between fruit that would ultimately be classified as striped or blushed.

The comparison of average hue angle for the whole peel at harvest from photographic data indicated that blushed fruit were significantly redder $(P<0.01)$ in all years $\left(14.0^{\circ}\right.$ versus $22.3^{\circ}, 10.8^{\circ}$ versus $14.0^{\circ}$, and $28.1^{\circ}$ versus $31.7^{\circ}$ for 2005,2006 , and 2007 , respectively).

The lack of consistent color differences throughout development in the reddest point of the fruit peel indicated that differences between blushed and striped fruit are only consistently detectable when measuring color for the whole peel. We cannot rule out that measurements of color in the whole peel like those performed from photographs at harvest might give different results in earlier dates, but such measurements are impractical before harvest because they require controlled light conditions. Given that blushed fruit are redder than striped ones, the goal should be to increase blushed fruit production when target markets prefer redder fruit.

Blushed and striped fruits did not accumulate anthocyanins in different layers of the peel (Fig. 5A-B). Both kinds of fruits showed anthocyanin accumulation in the epidermis and hypodermis; color intensity was related to the proportion of cells accumulating anthocyanins. In striped fruit, the difference between stripes was only the result of lack of anthocyanin accumulation in the paler stripes, and not the result of a deeper localization of the anthocyanin-containing cells (Fig. 5C-D) as proposed by McMeans et al. (1998) for the case of 'Gala' apple.

Among the trees that produced the highest percentages of blushed fruit throughout this study, all but one were originally blushed, but in no case was the percentage higher than $50 \%$ across all years. The absence of trees with consistently high percentage of blushed fruit highlights the importance of regulating crop load if the objective is to increase

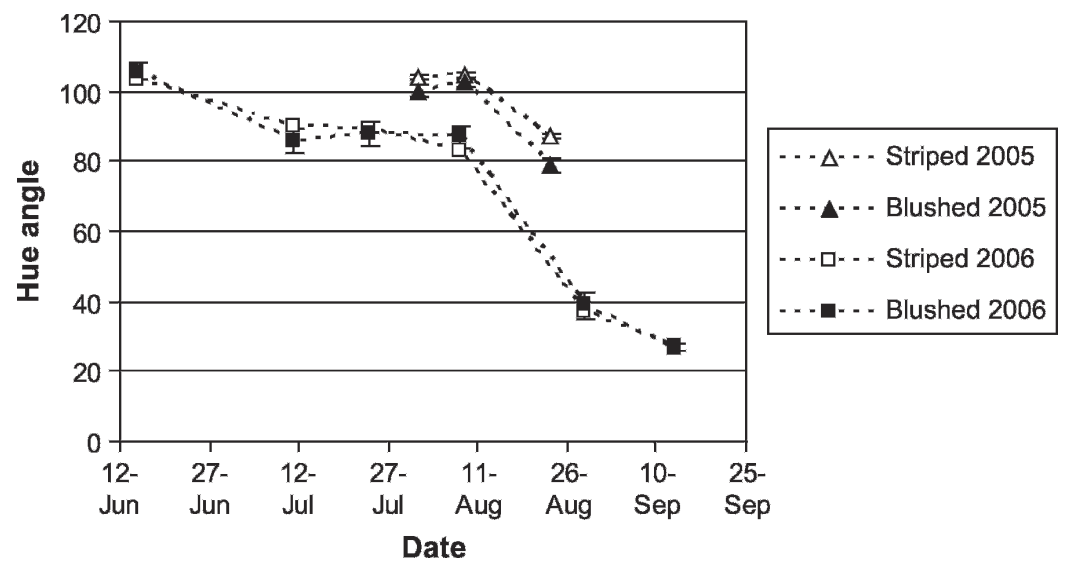

Fig. 4. Fruit peel hue angle measured at the reddest point of the fruit surface. Data points represent the average for all blushed or striped fruits measured on each date. Bars represent sEs.
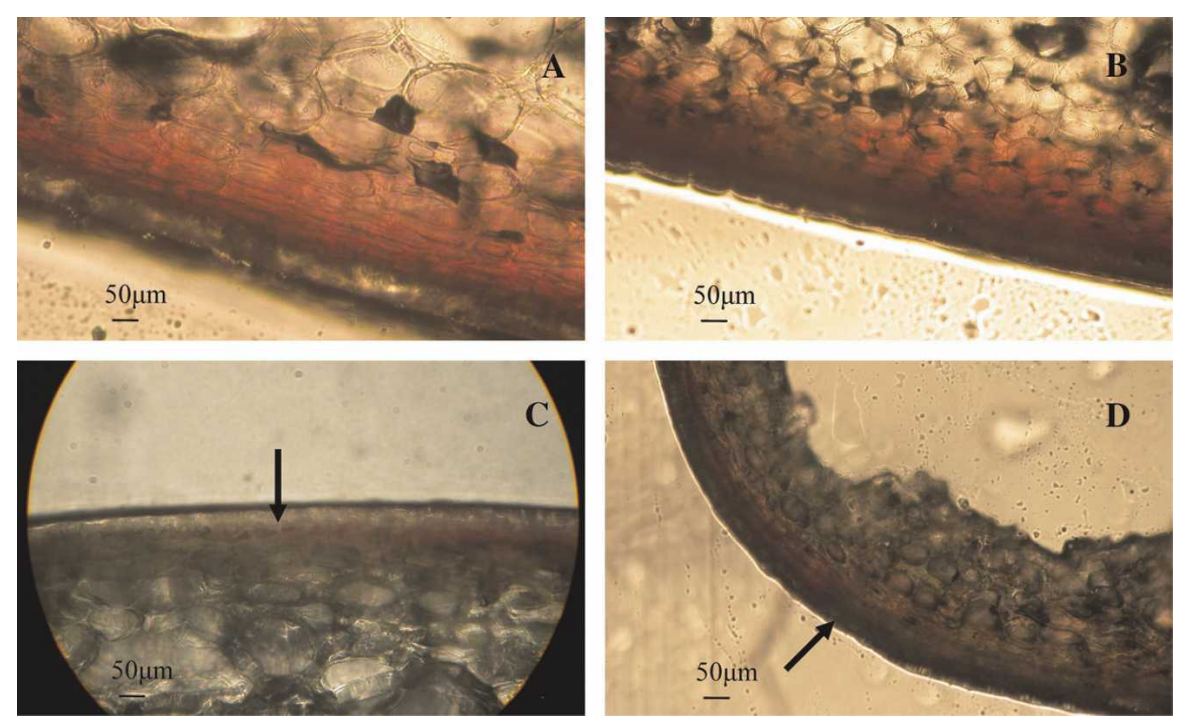

Fig. 5. Peel cross-sections of (A) a striped fruit, $(\mathbf{B})$ a blushed fruit, and (C-D) striped fruit showing the intersection of a red and a green stripe (indicated with an arrow).

blushed fruit production. Even then, reaching consistently high percentages of blushed fruit might be challenging under our conditions.

The tendency of blushed trees to produce a higher percentage of blushed fruit indicated that the blushed/striped trait in 'Honeycrisp' apple is partially conserved after asexual propagation. Given the significant environmental effects and that single plants and even single spurs produced both kinds of fruits, a strictly genetic control of the trait can be ruled out. These results also indicated that the blushed/striped phenomenon is probably not chimeral.

We speculate that an epigenetic mechanism (i.e., involving changes in gene function that do not involve changes in DNA sequence) controls the pattern of anthocyanin deposition in 'Honeycrisp' apple peels. Crop load and environmental effects can be some of the factors involved in the regulatory mechanism. Many examples of epigenetic mechanisms controlling pigment accumulation in plants have been described. In corn (Zea mays L.), variegated leaf phenotypes are the result of the accumulation of anthocyanin in some clonal sectors but not in others. According to Cocciolone and Cone (1993), differential DNA methylation in a gene controlling anthocyanin accumulation $(P l-B h)$ can account for the variation observed. Plants carrying the $\mathrm{Pl}-\mathrm{Bh}$ allele show sectors of pigmented and unpigmented cells. The authors propose that the $\mathrm{Pl}-\mathrm{Bh}$ gene is silenced through DNA methylation early in development in a portion of the cells. Cells subsequently divide resulting in sectors of predominantly pigmented cells (in which $\mathrm{Pl}$ $B h$ is unmethylated) and cells predominantly lacking pigment (methylated). Transposons are another likely explanation for the phenomenon observed; like differential methylation, transposon activity could be both maintained through cell division and environmentally regulated. Different kinds of transposons have been identified in apple to date (Antonius-Klemola et al., 2006; Han and Korban, 2007; Tignon et al., 2001; Venturi et al., 2005; Yao et al., 2001).

In summary, the blushed/striped phenomenon in 'Honeycrisp' apple is controlled both at the genetic and the environmental level, leading us to suggest an epigenetic mechanism of control. Increasing blushed fruit production, both through clonal selection and crop load regulation, should be the goal if apples with redder peels are desired. However, our results suggest that obtaining clones that produce exclusively striped or blushed fruit may be difficult. A tool for efficient relative color evaluations (or any other statistics of the segmented area that the user inputs) was developed and is freely available to the community.

\section{Literature Cited}

Antonius-Klemola, K., R. Kalendar, and A.H. Schulman. 2006. TRIM retrotransposons occur in apple and are polymorphic between varieties but not sports. Theor. Appl. Genet. 112:9991008 . 
Boyer, J. and R.H. Liu. 2004. Apple phytochemicals and their health benefits. Nutr. J. 3:3-17.

Cliff, M., K. Sandford, W. Wismer, and C. Hampson. 2002. Use of digital images for evaluation of factors responsible for visual preference of apples by consumers. HortScience 37:1127-1131.

Cocciolone, S.M. and K.C. Cone. 1993. Pl-Bh, an anthocyanin regulatory gene of maize that leads to variegated pigmentation. Genetics 135:575-588.

Cook, R.D. and S. Weisberg. 1999. Applied regression including computing and graphics. Wiley, New York, NY.

Dayton, D.F. 1959. Red color distribution in apple skin. J. Amer. Soc. Hort. Sci. 74:72-80.

Du, C.J. and D.W. Sunday. 2004. Recent developments in the applications of image processing techniques for food quality evaluation. Trends Food Sci. Technol. 15:230-249.

Duda, R.O., P.E. Hart, and D.G. Stork. 2001. Pattern classification. Wiley, New York, NY.

Eberhardt, M.V., C.Y. Lee, and R.H. Liu. 2000. Antioxidant activity of fresh apples. Nature 405:903-904.
Gonzalez, R.C. and R.E. Woods. 1992. Digital image processing. Addison-Wesley Reading, MA.

Han, Y. and S.S. Korban. 2007. Spring: A novel family of miniature inverted-repeat transposable elements is associated with genes in apple. Genomics 90:195-200.

Janick, J., J.N. Cummins, S.K. Brown, and M Hemmat. 1996. Apples, p. 1-77. In: Janick, J. and J.N. Moore (eds.). Fruit breeding. Wiley, New York, NY.

Knekt, P., R. Jarvinen, A. Reunanen, and J. Maatela. 1996. Flavonoid intake and coronary mortality in Finland: A cohort study. BMJ 312:478-481.

Le Marchand, L., S.P. Murphy, J.H. Hankin, L.R. Wilkens, and L.N. Kolonel. 2000. Intake of flavonoids and lung cancer. J. Natl. Cancer Inst. 92:154-160

Luby, J.J. and D.S. Bedford. 1992. Honeycrisp apple. Univ. Minn. Agr. Expt. Sta. Rpt. 2251992 (AD-MR-5877-B).

McGuire, R.G. 1992. Reporting of objective color measurements. HortScience 27:1254-1255.
McMeans, O., R.M. Skirvin, A. Otterbacher, and G. Mitiku. 1998. Assessment of tissue culturederived 'Gala' and 'Royal Gala' apples (Malus $\mathrm{x}$ domestica Borkh.) for somaclonal variation. Euphytica 103:251-257.

Royal Horticulture Society. 1995. The RHS colour chart. RHS, London, UK

Saure, M.C. 1990. External control of anthocyanin formation in apple: A review. Sci. Hort 42:181-218.

Tignon, M., B. Watillon, and R. Kettmann. 2001. Identification of copia-like retrotransposable element by apple. Acta Hort. 546:515-520.

Venturi, S., L. Dondini, P. Donini, and S. Sansavini. 2005. Retrotransposon characterisation and fingerprinting of apple clones by S-SAP markers. Theor. Appl. Genet. 112:440-444.

Yao, J., Y. Dong, and B. Morris. 2001. Parthenocarpic apple fruit production conferred by transposon insertion mutations in a MADSbox transcription factor. Proc. Natl. Acad. Sci. USA 98:1306-1311.

Zielinski, Q. 1977. Modern systematic pomology. Pomona Books, Ontario, Canada. 